\title{
Effects of chronically high levels of aldosterone on different cognitive dimensions: an investigation in patients with primary aldosteronism
}

\author{
Lukas Engler ${ }^{1}$, Christian Adolf', Daniel A Heinrich', Anna-Katharine Brem ${ }^{2,3}$, Anna Riester ${ }^{1}$, Anna Franke ${ }^{1}$, \\ Felix Beuschlein ${ }^{1}$, Martin Reincke ${ }^{1}$, Axel Steiger ${ }^{2}$ and Heike Künzel ${ }^{1}$ \\ ${ }^{1}$ Medizinische Klinik und Poliklinik IV, Klinikum der Universität München, LMU München, Munchen, Germany \\ ${ }^{2}$ Max-Planck-Institute of Psychiatry, Munich, Germany \\ ${ }^{3}$ Division of Interventional Cognitive Neurology, Department of Neurology, Berenson-Allen Center for Noninvasive Brain Stimulation, Beth Israel \\ Deaconess Medical Center, Harvard Medical School, Boston, Massachusetts, USA
}

Correspondence should be addressed to M Reincke: Martin.Reincke@med.uni-muenchen.de

\begin{abstract}
Primary aldosteronism is a natural model for chronic aldosterone excess in humans and associated with symptoms of anxiety and depression. Cognitive deficits are inherent to the symptomatology of depression and anxiety disorders. Mineralocorticoid receptors and aldosterone appear to play a role in memory. Aldosterone was additionally supposed to be a risk factor for cognitive decline in patients with essential hypertension. The objective of this study was to investigate possible effects of chronically high aldosterone concentrations on cognitive function. A range of cognitive dimensions were assessed in 19 patients ( 9 males, 10 females); mean age 47.1 (12.5) under standardized treatment and several rating scales for anxiety, depression, quality of life and sleep were administered. Cognitive parameters were compared to standard norms from a large, healthy standardization sample. Patients showed increased levels of anxiety and depression without meeting diagnostic criteria for a disorder. Besides a numerically lower attention score, patients did not show any significant differences in the cognitive dimensions. Anxiety and depression were negatively correlated with quantitative performance in males. In females, a negative correlation between sleep disturbances and abstract reasoning and a positive correlation with quantitative performance were found. Our data showed no specific effect of chronic aldosterone in the tested cognitive parameters overall at least in younger patients, but they indicate sexually dimorphic regulation processes.
\end{abstract}

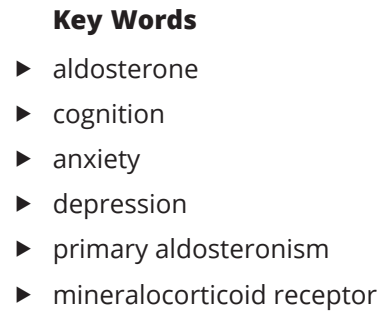

Endocrine Connections (2019) 8, 407-415

\section{Introduction}

Patients with primary aldosteronism (PA) are thought to be a natural model for chronic aldosterone excess, showing significantly higher scores for depression and anxiety compared to the general population, with females being more affected than males (1). These patients were also found to have a lower quality of life (QoL) even after treatment with either a mineralocorticoid receptor
(MR) antagonist or adrenalectomy (ADX) (2). Cognitive deficits are prevalent in depression $(3,4)$; however, the underlying pathophysiology is not fully clarified. Animal data emphasize the importance of a balanced MR/glucocorticoid receptor (GR) system for cognitive functions (5) and support the role of MR in memory functions. Furthermore the MR seems to be involved in 
emotional memory processes $(6,7,8)$. Both the MR and aldosterone appear to be involved in the pathophysiology of depression and anxiety $(9,10)$. Subchronic treatment with aldosterone resulted in increased anxiety and depression-like behaviour in rats. Furthermore changes in the transcription of hippocampal genes, which are involved in synaptic and neuronal remodelling were found $(11,12)$. Similar results were reported for depressionlike behaviour in rats after chronic treatment with a MR agonist (13). In humans, the MR has been shown to predict memory performance in depression (14) and blocking the MR in animals resulted in an impairment of the reference memory (15). After administration of the MR antagonist spironolactone in healthy male controls, impaired cognitive performance in selective attention, delayed recall and set shifting/mental flexibility was observed (16). In patients with depression, elevated aldosterone concentrations were described $(17,18)$, and polymorphisms in the angiotensin-converting enzyme (ACE) gene were reported to be associated with unipolar depression and hypercortisolism (19). Again hypertension itself has been found to be related to cognitive impairment and the development of dementia (20). Yagi et al. could additionally identify high plasma aldosterone as a risk factor for cognitive decline in patients with essential hypertension (21). Similar results were found in elder patients with essential hypertension. In these patients, aldosterone was associated with lower blood flow, and patients with higher concentrations of aldosterone were found to improve in cognitive functions when treating blood pressure (22).

The aim of the present study was to specify the effects of aldosterone on cognitive functions and gain insight into possible pathways of cognition mediated by MR and aldosterone.

\section{Methods}

\section{Patients}

Nineteen patients (nine males, ten females; mean age $47.1 \pm 12.5$ years; age range 18-66 years) with first diagnosed PA were enrolled in this study. Patients were prospectively recruited from the German Conn registry. All patients had to give their written informed consent and were investigated under standardized antihypertensive medication according to the conn-registry-protocol (a combination of verapamil, doxazosin and/or urapidil), not affecting the renin-aldosterone-angiotensine system (RAAS) (23). The diagnosis of PA was based on established criteria $(24,25,26)$. A full examination with regard to basic clinical and laboratory data and several psychiatric and neuropsychological scales was performed.

Patients doing shift work or suffering from jetlag, or being treated with spironolactone, any psychiatric drugs or hormonal therapy were excluded. Use of drugs or extensive abuse of alcohol was not allowed. Patients with further hormonal disturbances or known sleeping disorders were not enclosed.

The study was performed in accordance with the Declaration of Helsinki and with the 'Note for Guidance on Good Clinical Practice for Studies on Medical Products in the European Community, July 11, 1990'. The study was approved by the Ethical Committee of the University of Munich.

Investigations and psychiatric assessments were performed by physicians and medically trained staff. The neuropsychological and psychological testing was performed by professionally trained staff at the MaxPlanck-Institute of Psychiatry.

\section{Psychiatric scales}

Quality of life was assessed with the SF-12 questionnaire, a validated, multipurpose measure, which can discriminate between mental and physical aspects of quality of life (27). Reference values were set by the norm sample of the German population (1994) (SF-12 Manual).

To assess depression and anxiety, we performed the Beck Inventory of Depression (BDI), the Patient Health Questionnaire-9 (PHQ-9), the Hamilton Rating Scale for Depression (HAM-D), the generalized anxiety disorder questionnaire (GAD-7) and the Hamilton Anxiety Rating Scale (HAM-A).

The BDI, the HAM-D and the PHQ-9 are validated measuring scales widely used for screening, diagnosing and specifying the severity of depression $(28,29,30)$. The HAM-A and GAD-7 are instruments to identify and quantify the extent of anxiety $(30,31)$.

Reference data for the BDI were provided by Beck et al. (29). Scores of 1-10 indicate no depression, scores from $10-19,20-29$ and $\geq 30$ indicate a mild, moderate or severe depressive syndrome, respectively $(32,33)$.

Concerning the HAM-D, reference data were provided by Zimmerman et al. (34). A score of $\leq 8$ indicates no depression, a mild depressive syndrome was defined for the range of 9-16 points, a moderate syndrome for 17-24 points and a severe syndrome for $\geq 25$ points (33).

Reference data for the PHQ-9 was taken by Rief $e t$ al. (35). Scores of 5, 10, 15 and 20 represented cut-points

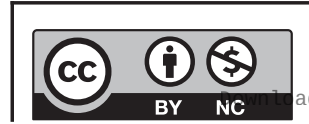

This work is licensed under a Creative Commons Attribution-NonCommercial 4.0 International License. ded from Bioscientifica.com at 04/26/2023 01:14:16PM 
for mild, moderate, moderately severe and severe depression, respectively (36).

Concerning the GAD-7, normative data of the German population was defined by Lowe et al. (37). According to the cut-offs set by Spitzer et al. (31), scores of 5, 10 and 15 represent cut-off points for mild, moderate and severe anxiety.

We used the HAM-A grading of severity suggested by Hamilton et al. (38). Ranges of 14-17, 18-24 and 25-30 points indicate a mild, moderate or moderate-to-severe level of anxiety.

Sleep quality was measured with the Pittsburgh Sleep Quality Index (PSQI). The PSQI is able to evaluate retrospectively the quality and patterns of sleep over a time interval of 1 month by observing seven different components which can be combined in a global score (39). Additionally, we performed the following three sum scores to gain further insight to sleep quality:

(1) 'Sleep Efficiency Sum Score' composed of 'Sleep Duration' and 'Sleep Efficiency'; (2) 'Perceived Sleep Quality Sum Score' composed of 'Subjective Sleep Quality', 'Sleep Latency' and 'Use of Sleeping Medication'; (3) 'Daily Disturbances Sum Score' composed of 'Sleep Disturbances' and 'Daytime Dysfunction'.

PSQI reference values from the Austrian population were used (40).

Daily fatigue was assessed with the Epworth Sleepiness Scale (ESS) (41) using German normative values (42).

\section{Neuropsychological assessment}

Neuropsychological testing was performed in the morning. Cognitive performance was evaluated using the $\mathrm{d} 2$ test for attention (d2), a validated test to rate selective attention and concentration (43). Test parameters for quantitative performance were total number of items processed ('GZ') and total number of items minus errors, i.e., number of correctly marked items ('GZ-F'). Qualitative performance was represented by the percentage of errors ('F\%').

Logical memory was evaluated with the Revised Wechsler Memory Scale (44), which examines immediate ('Logical Memory I') and delayed ('Logical Memory II' after $30 \mathrm{~min}$ ) text reproduction. Executive abilities were assessed with two subtests of the Wechsler Test of Intelligence (WIE). 'Matrices' measures abstract reasoning and fluid intelligence. The 'Digit-Symbol-Test' (DST) assesses processing speed (45). To observe genderdependent differences, raw data of the different scales were compared. Patients' cognitive parameters were compared to normal values of the general population.

\section{Hormone assays}

Blood draw for the laboratory routine and hormones cortisol and aldosterone was performed in a standardized procedure in the morning after resting for $10 \mathrm{~min}$. Plasma aldosterone concentrations were measured using a commercial radioimmunoassay (DiaSorin Liasion CLIA Aldosteron ng/L). Plasma renin concentrations were determined using a chemiluminescence immunoassay (ReninLiason Diasorin Liaison Act. 4.4-64 $\mu \mathrm{U} / \mathrm{mL}$, Italy). Cortisol was measured with a chemiluminescence immunoassay (Liaison Diasorin REF 313261).

\section{Statistical analysis}

Statistical analyses were carried out in SPSS Statistics for Windows, version 23 (IBM). Analysis of variance with age as a covariate (ANCOVA) was performed to examine sex differences. To detect the possible associations, bivariate correlation analyses with Pearson's coefficient were performed for interval-scaled variables. Canonical correlations were performed to detect the possible multivariate correlations. To minimize the impact of missing data in the canonical correlation analysis, mean imputation was used. For all statistical tests, a $P$ value of $<0.05$ was set as the limit for statistical significance. Questionnaires that were incompletely answered or had missing values were excluded from further analysis.

\section{Results}

\section{Basic clinical data}

All patients displayed elevated 24-h mean blood pressure (BP) values for both systolic and diastolic BP (mean: $148 \pm 96 \mathrm{mmHg}$ ). In comparison to female participants, males displayed significantly higher BP. The BMI was numerically higher, the waist-to-hip ratio was significantly higher in males $(P=0.001)$. No statistical significance between the sexes was observed in clinical laboratory data (Table 1). Six out of ten females have been postmenopausal. Sex hormones have not been assessed. Cortisol co-secretion was assessed in 15 patients with dexamethasone suppression test (DST) and salivary profile. Only one female patient had an elevated cortisol concentration in the salivary profile. Serum cortisol was within the normal ranges for all patients.

\section{Neuropsychological assessment}

Raw scores of male and female patients did not differ significantly in any of the neuropsychological parameters

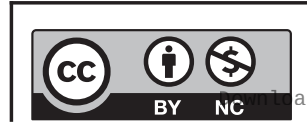

This work is licensed under a Creative Commons Attribution-NonCommercial 4.0 International License. ded from Bioscientifica.com at 04/26/2023 01:14:16PM 
Table 1 Clinical data of the patients studied. Bold indicates statistical significance. Italics indicate reference values.

Number $(N)$

Mean age (years)

Mean time until first diagnosis (months)

Mean $24 \mathrm{~h}$ systolic BP $(\mathrm{mmHg})$

Mean $24 \mathrm{~h}$ diastolic BP $(\mathrm{mmHg})$

Mean systolic BP at daytime $(\mathrm{mmHg})$

Mean diastolic BP at daytime $(\mathrm{mmHg})$

Mean systolic BP at night $(\mathrm{mmHg})$

Mean diastolic BP at night $(\mathrm{mmHg})$

Waist-to-hip ratio

BMI $\left(\mathrm{kg} / \mathrm{m}^{2}\right)$

Serum sodium $(\mathrm{mmol} / \mathrm{L})(135-150 \mathrm{mmol} / \mathrm{L})$

Serum potassium $(\mathrm{mmol} / \mathrm{L})(3.5-5.0 \mathrm{mmol} / \mathrm{L})$

Serum cortisol $(\mu \mathrm{g} / \mathrm{dL})(1.8-24.0 \mu \mathrm{g} / \mathrm{dL})$

Serum aldosterone (ng/L) (40-310 $\mathrm{ng} / \mathrm{L})$

Plasma renin concentration $(\mu \mathrm{U} / \mathrm{L})(8-99 \mu \mathrm{U} / \mathrm{mL})$

Aldosterone/renin ratio $(<20 \mathrm{ng} / \mathrm{L} / \mathrm{mU} / \mathrm{L})$

GZ (raw data)

$\mathrm{GZ}$

GZ-F (raw data)

GZ-F

$\mathrm{F} \%$ (raw data)

$\mathrm{F} \%$

Logical memory I (raw data)

Logical memory I

Logical memory II (raw data)

Logical memory II

Matrices (WIE) (raw data)

Matrices (WIE)

DST (WIE) (raw data)

DST (WIE)

PHQ-9

Reference value (RV) (cut-off: <5)

HAM-D

RV (cut-off: $\leq 8)$

BDI (cut-off: <10)

GAD-7

RV (cut-off: <5)

HAM-A

RV (cut-off: <14)

SF-12; PCS

RV

SF-12; MCS

RV

ESS

RV

PSQI-global score

RV

PSQI-subjective sleep quality

$\mathrm{RV}$

PSQI-sleep latency

RV

PSQI-sleep duration

RV

PSQI-habitual sleep efficiency

RV

PSQI-sleep disturbances

RV

PSQI-use of sleeping medication

$\mathrm{RV}$

PSQI-daytime dysfunction

RV

PSQI-sleep efficiency sum score

PSQI-perceived sleep quality sum score

PSQI-daily disturbances sum score
Whole group (s.)

19

$47.1(12.5)$

$112.8(101.8)$

$148(15)$

96 (9)

$150(16)$

97 (10)

$141(14)$

89 (10)

$0.9(0.1)$

27.2 (3.9)

$141(3)$

$3.5(0.5)$

$13(4)$

231 (184)

4.4 (3.8)

79.8 (75.9)

404 (48)

29.6 (18.2)

390 (46)

33.4 (19.8)

3.8 (2.9)

64.6 (23.6)

27.9 (6.3)

52.7 (32.2)

$25.1(6.2)$

$52.3(30.3)$

$17.2(6.0)$

59.5 (28.7)

$74.1(10.9)$

$62.0(25.6)$

$6.5(5.3)$

$3.56(4.08)$

$5.8(5.5)$

$3.2(3.2)$

$4.2(6.2)$

$5.6(5.6)$

$2.95(3.41)$

7.4 (7.1)

$45.3(12.1)$

50.8 (9.1)

8.1 (4.7)

$6.6(3.5)$

$6.4(4.1)$

$4.55(3.71)$

$1.4(0.7)$

$0.75(0.78)$

$1.3(1.0)$

$0.88(0.85)$

$0.9(0.9)$

$0.74(0.71)$

$0.5(0.9)$

$0.31(0.71)$

$1.3(0.7)$

$0.83(0.99)$

$0.0(0.0)$

$0.23(0.68)$

$1.0(0.9)$

$0.82(0.76)$

$1.4(1.7)$

2.7 (1.5)

$2.3(1.5)$

\section{PA men (S.D.)}

A men (S.D.)

48.4 (10.9)

$113.3(65.3)$

$154(18)$

100 (8)

155 (20)

101 (10)

150 (13)

$96(5)$

$0.9(0.1)$

28.8 (3.6)

141 (3)

$3.4(0.4)$

14 (4)

200 (138)

4.6 (4.9)

84.2 (95.9)

420 (42)

35.4 (19.5)

404 (43)

38.5 (23.1)

4.5 (2.2)

$56.8(18.2)$

$28.4(5.7)$

$57.3(28.4)$

$25.3(6.0)$

54.8 (24.9)

$18.8(6.2)$

$66.0(28.4)$

74.9 (9.1)

$60.4(28.4)$

$5.8(5.8)$

$3.2(2.7)$

$3.3(3.3)$

$2.1(3.4)$

3.6 (3.5)

$2.66(3.24)$

4.8 (4.9)

46.8 (11.7)

$50.2(8.68)$

$51.0(7.5)$

$53.25(7.57)$

$8.8(4.6)$

$6.9(3.3)$

6.1 (4.7)

$1.3(0.7)$

1.00 (1.0)

$1.00(1.0)$

$0.3(1.0)$

$1.2(0.7)$

$0.0(0.0)$

$1.2(1.2)$

1.3 (1.9)

$2.3(1.5)$

$2.4(1.5)$

\begin{tabular}{c}
\hline PA women (S.D.) \\
\hline 10 \\
$45.9(14.3)$ \\
$112.5(130.3)$ \\
$143(8)$ \\
$91(8)$
\end{tabular}

145 (11)

$92(8)$

131 (6)

81 (9)

$0.8(0.1)$

25.7 (3.8)

140 (3)

$3.6(0.6)$

$12(4)$

258 (222)

4.1 (2.5)

$75.8(57.5)$

389 (51)

23.9 (16.0)

377 (49)

28.4 (15.9)

$3.0(3.4)$

72.5 (26.8)

$27.5(7.2)$

48.1 (36.9)

$24.9(6.8)$

49.8 (36.6)

$15.6(5.7)$

$53.0(29.4)$

73.3 (13.2)

$63.6(24.2)$

7.4 (4.9)

$8.4(6.4)$

$3.1(3.2)$

6.6 (7.9)

$7.9(6.8)$

$3.20(3.52)$

$10.1(8.1)$

43.0 (13.4)

$47.9(9.74)$

50.6 (11.9)

$51.30(8.41)$

7.4 (4.9)

$6.2(3.7)$

6.7 (3.8)

$1.6(0.8)$

$1.6(0.9)$

$0.9(1.1)$

$0.7(0.8)$

$1.3(0.8)$

$0.0(0.0)$

$0.7(0.5)$

$1.6(1.6)$

3.1 (1.6)

$2.0(1.2)$
0.359

P value

-

0.124

0.023

0.217

0.114

0.002

$<0.001$

0.001

0.104

0.765

0.317

0.508

0.534

0.702

0.889

0.222

0.277

0.276

0.813

0.926

0.190

0.800

0.525

0.025

0.118

0.076

0.153

0.416

0.936

0.427

0.675

0.462

0.141

0.907

0.411

0.714

-

0.719

0.194

0.668 https://ec.bioscientifica.com

https://doi.org/10.1530/EC-19-0043 


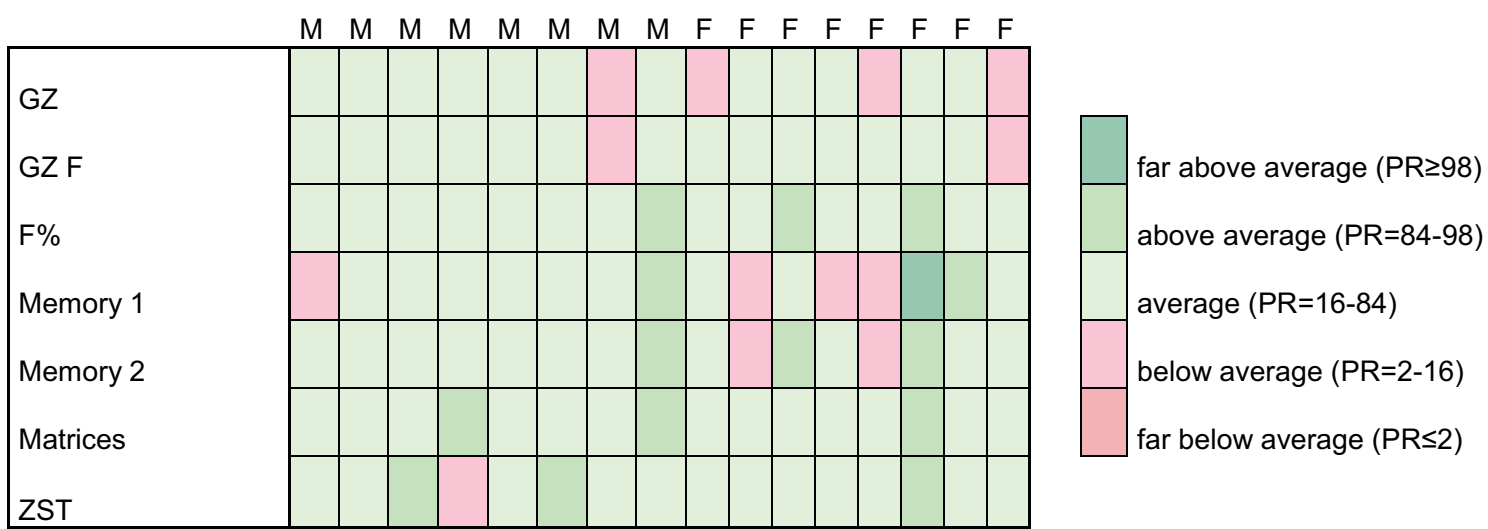

Figure 1

Neuropsychological assessment. Indication of individual data for males and females according to their neuropsychological performance.

(Table 1). In comparison with a norm sample, patients' performance was average for most of the measures. Isolated impairments $(\mathrm{PR} \leq 16)$ could be observed in memory and attention measures, whereas half of the subjects showed impairment in at least one cognitive parameter. None of the values were far below average $(\mathrm{PR}<2)$ (Fig. 1).

\section{Psychiatric scales}

On average, female PA patients scored higher in all psychiatric scales in comparison with male PA patients. Concerning the HAM-D score, difference reached statistical significance in favour of the female participants $(P=0.025)$ (Table 1$)$.

Referring to the depression-related scales, PA participants showed a mild depression severity in the PHQ-9.

Regarding the BDI and the HAM-D, the PA group stayed below the cut-off for a considerable depression severity. But when analysed separately for gender, females showed higher scores than males.

In terms of anxiety-related scales, the PA group achieved higher GAD-7 means in comparison to the German reference data (37). Female participants showed a mild anxiety disorder, male ones stayed below the cut-off.

Evaluating the HAM-A study group score, our group stayed below the cut-off set by Hamilton et al. (38).

\section{SF-12}

In both the physical (PCS) and the mental (MCS) SF-12 subscale, female PA participants in comparison to male PA participants showed lower mean values without reaching statistical significance. Referring to the German reference data (SF-12 Manual), the PA group explored in the present study showed lower mean values in both subscales.

\section{Sleep questionnaires: ESS and PSQI}

\section{ESS}

Male PA patients scored higher in comparison to female PA patients without reaching statistical significance $(P=0.427)$. Compared to the population-based study by Sauter et al. (42), higher scores were found in the PA group in the whole group (Table 1).

\section{PSQI}

Female PA participants achieved higher scores in the global PSQI score as well as in all PSQI subscales, except the 'Daily Disturbances Sum Score', the 'Sleep Duration Component Score' and the 'Daytime Dysfunction Component Score' without reaching statistical significance (Table 1 for $P$ values). Referred to the normative study by Zeitlhofer et al. (40), the PA group showed higher mean values in the global PSQI score as well as in all PSQI subscale scores except for the 'Use of sleeping medication subscale' score (Table 1).

\section{Significant correlations}

Significant correlations including the neuropsychological variables are listed in Table 2 . On a multivariate level, no significant correlations appeared. Observing bivariate associations, the total number of items processed ('GZ') showed negative associations with depression- as well as anxiety-related scales. These negative associations were partly present in the male PA subgroup without equivalent in the female PA subgroup.
This work is licensed under a Creative Commons Attribution-NonCommercial 4.0 International License. ded from Bioscientifica.com at 04/26/2023 01:14:16PM via free access 
Table 2 Significant correlations.

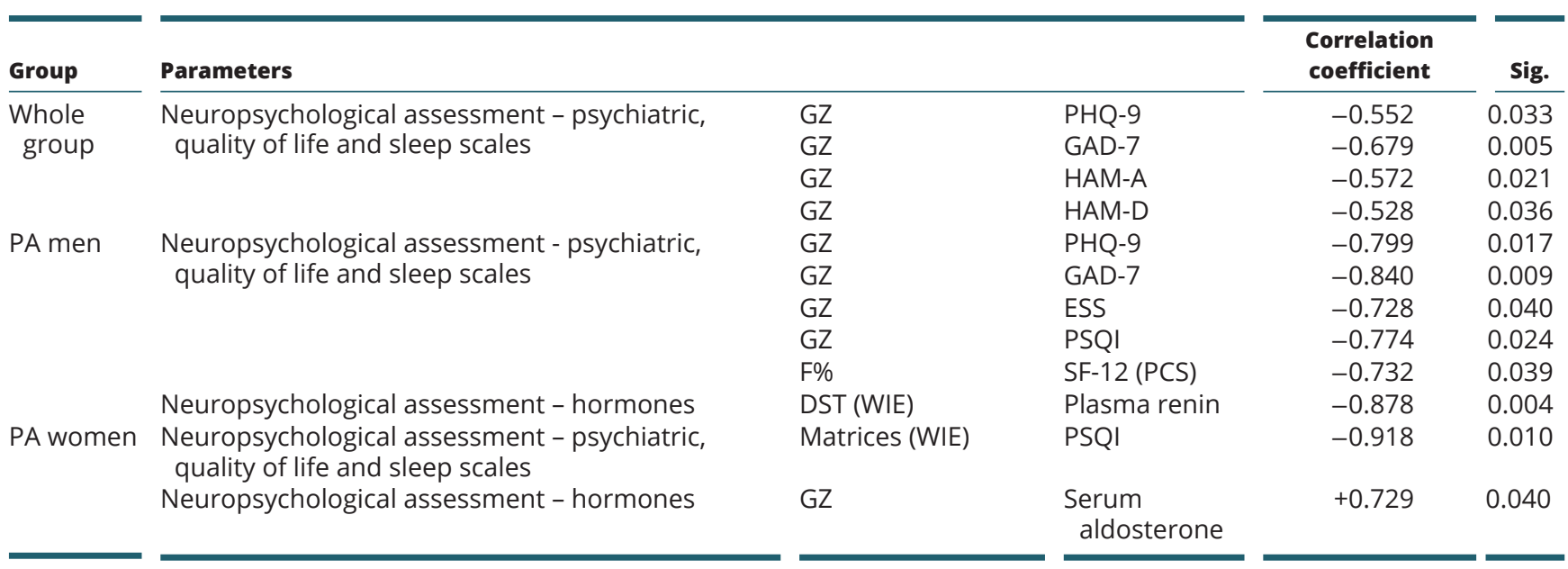

Additionally, the percentage of errors (' $\mathrm{F} \%$ ') correlated negatively with the Physical Health Composite Scale score (PCS) of the SF-12 in the male PA group.

Both male and female PA participants showed a negative correlation between the PSQI and neuropsychological parameters, the negative association including the ESS was limited to the male PA group.

Observing hormonal associations, neuropsychological parameters correlated negatively with the plasma renin concentration in the male PA group and positively with serum aldosterone levels in the female PA group.

\section{Discussion}

The aim of our study was to shed light on the effects of aldosterone and MR on attention and memory functions in patients with PA treated with standardised medication. Although patients with a manifest psychiatric disorder according to DSM-IV were excluded, anxiety and depressive symptoms were elevated and QoL was reduced with higher affection in female patients as described in previous studies $(1,2)$. Sleep quality measured by PSQI was subjectively impaired in PA. All patients scored within the norm values of the general population in all tested cognitive dimensions (attention, logical memory, executive functions). No significant differences between male and female patients were detected. However, half of the participants showed at least impairment in memory and attention measures.

Overall, a significant negative correlation for quantitative performance, measured with GZ and depression and anxiety was found; gender-specific analyses revealed that this effect was only significant in males. Males experiencing anxiety and depression as well as sleep disturbances and daytime sleepiness are significantly negatively correlated with quantitative performance, meaning a deceleration in their processing speed. Qualitative performance was negatively correlated with physical subscale in males. The cognitive profile of male patients was otherwise neither comparable to patients with anxiety disorders, for whom impairments in attention, memory and emotional intelligence have been described (46), nor patients with depression, for whom impairments in attention, executive functions and memory have been reported (47). In females, GZ was positively correlated to aldosterone. Although the number of subjects is small, this finding is not in line with the assumption of aldosterone being a risk factor for cognitive impairment $(21,22)$. Only in females, subjective sleep quality in the PSQI had a negative influence on executive functions measure by abstract reasoning.

The absence of specific patterns in cognitive impairment could be explained by the fact that patients did not reach DSM-IV or ICD-10 criteria to be diagnosed with a depression or anxiety disorder, but only showed elevated levels of symptoms compared with the general population.

Neuropsychological dimensions were not systematically associated with any of the physical parameters such as BP or aldosterone. There are hints that aldosterone is associated with lower cerebrovascular function in hypertension $(21,22)$ and the association between early-stage Alzheimer's disease and plasma reninangiotensin-system aminopeptidase activities could be gender specific (48). We found significant correlations between aldosterone and GZ in females and plasma renin and DST in males, but further investigation is warranted. Differences to other studies might be explained by the

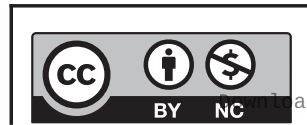

This work is licensed under a Creative Commons Attribution-NonCommercial 4.0 International License. ded from Bioscientifica.com at 04/26/2023 01:14:16PM via free access 
younger age of our patients in contrast to patients of the other studies.

Several studies investigated the role of the MR, the main target of aldosterone, in memory processes. These studies suggest MR to be mainly involved in fear memory and emotional arousal as well as the processing of this information (49). In our sample of patients with PA, chronic exposure to high concentrations of aldosterone did not show marked effects on cognition. This is in contrast to previous finding in healthy male subjects, in whom acute blocking of the MR with spironolactone resulted in consecutive impairment in several cognitive dimensions (16). These contrasting findings could be due to different underlying mechanisms associated with chronic exposure to aldosterone versus acute blockade with a MR antagonist. Sex differences in memory functions related to MR function have been described in animal data (50) and sexually dimorphic regulation of the MR- and gender-specific effects of aldosterone are at least described for other tissues $(51,52)$.

Chronic aldosterone excess seems not to influence immediate and delayed memory, cognitive and quantitative performance, abstract reasoning and the processing speed in our younger sample systematically. Emotional memory processes should be investigated further. Sexually dimorphic regulation processes in effects of aldosterone and MR-mediated processes are indicated by these data, because aldosterone was significantly associated with quantitative performance in women.

This study is limited by a small number of patients. Due to the small group of female patients, no analytical discrimination in pre- and postmenopausal status was done. A comparison with hypertensive patients would be interesting in future studies. Strengths of this study are an investigation under standardized conditions and a very good characterisation that enabled to assess possible interfering factors like fatigue or sleeping disturbances.

\section{Declaration of interest}

$\mathrm{F}$ Beuschlein is a member of the editorial board of Endocrine Connections. $\mathrm{F}$ Beuschlein was not involved in the review or editorial process for this paper, on which he is listed as an author. The other authors have nothing to disclose.

\section{Funding}

This work was supported by the Else Kröner-Fresenius Stiftung in support of the German Conns Registry-Else-Kröner Hyperaldosteronism Registry (2013_A182 and 2015_A171 to M R), the European Research Council (ERC) under the European Union's Horizon 2020 research and innovation programme (grant agreement No. (694913) to M R) and by the Deutsche Forschungsgemeinschaft (DFG) (within the CRC/Transregio 205/1 'The Adrenal: Central Relay in Health and Disease' to M R).

\section{Acknowledgments}

Specials thanks to Friederike Konrad, Susanne Schmid, Nina Nirschl, Lisa Sturm and Doreen Schmidt for their great support in conducting this study and to Alexander Yassouridis for his statistical support.

\section{References}

1 Apostolopoulou K, Kunzel HE, Gerum S, Merkle K, Schulz S, Fischer E, Pallauf A, Brand V, Bidlingmaier M, Endres S, et al. Gender differences in anxiety and depressive symptoms in patients with primary hyperaldosteronism: a cross-sectional study. World Journal of Biological Psychiatry 201415 26-35. (https://doi.org/10.3109/156229 75.2012.665480)

2 Kunzel HE, Apostolopoulou K, Pallauf A, Gerum S, Merkle K, Schulz S, Fischer E, Brand V, Bidlingmaier M, Endres S, et al. Quality of life in patients with primary aldosteronism: gender differences in untreated and long-term treated patients and associations with treatment and aldosterone. Journal of Psychiatric Research 201246 1650-1654. (https://doi.org/10.1016/j.jpsychires.2012.08.025)

3 Bora E, Harrison BJ, Yucel M \& Pantelis C. Cognitive impairment in euthymic major depressive disorder: a meta-analysis. Psychological Medicine 201343 2017-2026. (https://doi.org/10.1017/ S0033291712002085)

4 Wagner S, Doering B, Helmreich I, Lieb K \& Tadic A. A metaanalysis of executive dysfunctions in unipolar major depressive disorder without psychotic symptoms and their changes during antidepressant treatment. Acta Psychiatrica Scandinavica 2012125 281-292. (https://doi.org/10.1111/j.1600-0447.2011.01762.x)

5 Brinks V, van der Mark MH, de Kloet ER \& Oitzl MS. Differential MR/GR activation in mice results in emotional states beneficial or impairing for cognition. Neural Plasticity 20072007 90163. (https:// doi.org/10.1155/2007/90163)

6 Ferguson D \& Sapolsky R. Overexpression of mineralocorticoid and transdominant glucocorticoid receptor blocks the impairing effects of glucocorticoids on memory. Hippocampus 200818 1103-1111. (https://doi.org/10.1002/hipo.20467)

7 Schulz K \& Korz V. Emotional and cognitive information processing: relations to behavioral performance and hippocampal long-term potentiation in vivo during a spatial water maze training in rats. Learning and Memory 201017 552-560. (https://doi.org/10.1101/ $\operatorname{lm} .1855610)$

8 Zhou M, Bakker EH, Velzing EH, Berger S, Oitzl M, Joels M \& Krugers HJ. Both mineralocorticoid and glucocorticoid receptors regulate emotional memory in mice. Neurobiology of Learning and Memory 201094 530-537. (https://doi.org/10.1016/j. nlm.2010.09.005)

9 de Kloet ER. From receptor balance to rational glucocorticoid therapy. Endocrinology 2014155 2754-2769. (https://doi. org/10.1210/en.2014-1048)

10 Holsboer F. The corticosteroid receptor hypothesis of depression. Neuropsychopharmacology 200023 477-501. (https://doi.org/10.1016/ S0893-133X(00)00159-7)

11 Hlavacova N \& Jezova D. Chronic treatment with the mineralocorticoid hormone aldosterone results in increased anxietylike behavior. Hormones and Behavior 200854 90-97. (https://doi. org/10.1016/j.yhbeh.2008.02.004)

12 Hlavacova N, Wes PD, Ondrejcakova M, Flynn ME, Poundstone PK, Babic S, Murck H \& Jezova D. Subchronic treatment with aldosterone induces depression-like behaviours and gene expression changes relevant to major depressive disorder. International Journal of Neuropsychopharmacology 201215 247-265. (https://doi.org/10.1017/ S1461145711000368)

13 Johnson AK \& Grippo AJ. Sadness and broken hearts: neurohumoral mechanisms and co-morbidity of ischemic heart disease and

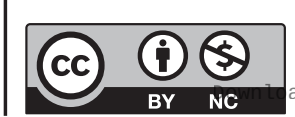

This work is licensed under a Creative Commons Attribution-NonCommercial 4.0 International License. ded from Bioscientifica.com at 04/26/2023 01:14:16PM 
psychological depression. Journal of Physiology and Pharmacology 2006 57 (Supplement 11) 5-29.

14 Keller J, Gomez R, Williams G, Lembke A, Lazzeroni L, Murphy GM Jr \& Schatzberg AF. HPA axis in major depression: cortisol, clinical symptomatology and genetic variation predict cognition. Molecular Psychiatry 201722 527-536. (https://doi.org/10.1038/mp.2016.120)

15 Douma BR, Korte SM, Buwalda B, la Fleur SE, Bohus B \& Luiten PG. Repeated blockade of mineralocorticoid receptors, but not of glucocorticoid receptors impairs food rewarded spatial learning. Psychoneuroendocrinology 199823 33-44. (https://doi.org/10.1016/ S0306-4530(97)00091-7)

16 Otte C, Moritz S, Yassouridis A, Koop M, Madrischewski AM, Wiedemann K \& Kellner M. Blockade of the mineralocorticoid receptor in healthy men: effects on experimentally induced panic symptoms, stress hormones, and cognition. Neuropsychopharmacology 200732 232-238. (https://doi.org/10.1038/sj.npp.1301217)

17 Emanuele E, Geroldi D, Minoretti P, Coen E \& Politi P. Increased plasma aldosterone in patients with clinical depression. Archives of Medical Research 200536 544-548. (https://doi.org/10.1016/j. arcmed.2005.03.046)

18 Murck H, Schussler P \& Steiger A. Renin-angiotensin-aldosterone system: the forgotten stress hormone system: relationship to depression and sleep. Pharmacopsychiatry 201245 83-95. (https:// doi.org/10.1055/s-0031-1291346)

19 Baghai TC, Binder EB, Schule C, Salyakina D, Eser D, Lucae S, Zwanzger P, Haberger C, Zill P, Ising M, et al. Polymorphisms in the angiotensin-converting enzyme gene are associated with unipolar depression, ACE activity and hypercortisolism. Molecular Psychiatry 200611 1003-1015. (https://doi.org/10.1038/sj.mp.4001884)

20 Nagai M, Hoshide S \& Kario K. Hypertension and dementia. American Journal of Hypertension 201023 116-124. (https://doi.org/10.1038/ ajh.2009.212)

21 Yagi S, Akaike M, Aihara K-i, Iwase T, Yoshida S, SumitomoUeda Y, Ikeda Y, Ishikawa K, Matsumoto T \& Sata M. High plasma aldosterone concentration is a novel risk factor of cognitive impairment in patients with hypertension. Hypertension Research 201134 74-78. (https://doi.org/10.1038/hr.2010.179)

22 Hajjar I, Hart M, Mack W \& Lipsitz LA. Aldosterone, cognitive function, and cerebral hemodynamics in hypertension and antihypertensive therapy. American Journal of Hypertension 201528 319-325. (https://doi.org/10.1093/ajh/hpu161)

23 Schirpenbach C, Segmiller F, Diederich S, Hahner S, Lorenz R, Rump LC, Seufert J, Quinkler M, Bidlingmaier M, Beuschlein F, et al. The diagnosis and treatment of primary hyperaldosteronism in Germany - results on 555 patients from the German Conn registry. Deutsches Ärzteblatt International 2009106 305-311. (https://doi. org/10.3238/arztebl.2009.0305)

24 Funder JW, Carey RM, Fardella C, Gomez-Sanchez CE, Mantero F, Stowasser M, Young WF Jr, Montori VM \& Endocrine Society. Case detection, diagnosis, and treatment of patients with primary aldosteronism: an endocrine society clinical practice guideline. Journal of Clinical Endocrinology and Metabolism 200893 3266-3281. (https://doi.org/10.1210/jc.2008-0104)

25 Schirpenbach C \& Reincke M. Epidemiology and etiology of therapy-resistant hypertension. Internist 200950 7-16. (https://doi. org/10.1007/s00108-008-2194-9)

26 Schirpenbach C, Segmiller F, Diederich S, Hahner S, Lorenz R, Rump LC, Seufert J, Quinkler M, Bidlingmaier M, Beuschlein F, et al. The diagnosis and treatment of primary hyperaldosteronism in Germany: results on 555 patients from the German Conn registry. Deutsches Ärzteblatt International 2009106 305-311. (https://doi. org/10.3238/arztebl.2009.0305)

27 Jenkinson C, Layte R, Jenkinson D, Lawrence K, Petersen S, Paice C $\&$ Stradling J. A shorter form health survey: can the SF-12 replicate results from the SF-36 in longitudinal studies? Journal of Public Health
Medicine 199719 179-186. (https://doi.org/10.1093/oxfordjournals. pubmed.a024606)

28 Gräfe K, Zipfel S, Herzog W \& Löwe B. Screening psychischer Störungen mit dem 'Gesundheitsfragebogen für Patienten (PHQ-D)': Ergebnisse der deutschen Validierungsstudie. Diagnostica 2004 Jg. 50 171-181. (https://doi.org/10.1026/0012-1924.50.4.171)

29 Beck AT, Steer RA \& Carbin MG. Psychometric properties of the Beck depression inventory: twenty-five years of evaluation. Clinical Psychology Review 19888 77-100. (https://doi.org/10.1016/02727358(88)90050-5)

30 Bech P. Fifty years with the Hamilton scales for anxiety and depression. A tribute to Max Hamilton. Psychotherapy and Psychosomatics 200978 202-211. (https://doi. org/10.1159/000214441)

31 Spitzer RL, Kroenke K, Williams JB \& Lowe B. A brief measure for assessing generalized anxiety disorder: the GAD-7. Archives of Internal Medicine 2006166 1092-1097. (https://doi.org/10.1001/ archinte.166.10.1092)

32 Meijer OC \& de Kloet ER. A role for the mineralocorticoid receptor in a rapid and transient suppression of hippocampal 5-HT1A receptor mRNA by corticosterone. Journal of Neuroendocrinology 19957 653-657. (https://doi.org/10.1111/j.1365-2826.1995. tb00804.x)

33 DGPPN, BÄK, KBV, AWMF, AkdÄ, BPtK, BApK, DAGSHG, DEGAM, DGPM, DGPs, DGRW. AWMF S3-Guideline/National Disease Management Guideline: Unipolar Depression. Berlin, Germany: DGPPN, ÄZQ, AWMF, 2015. (available at: https://www.leitlinien.de/nvl/ depression)

34 Zimmerman M, Chelminski I \& Posternak M. A review of studies of the Hamilton depression rating scale in healthy controls: implications for the definition of remission in treatment studies of depression. Journal of Nervous and Mental Disease 2004192 595-601. (https://doi.org/10.1097/01.nmd.0000138226.22761.39)

35 Rief W, Nanke A, Klaiberg A \& Braehler E. Base rates for panic and depression according to the Brief Patient Health Questionnaire: a population-based study. Journal of Affective Disorders $2004 \mathbf{8 2}$ 271-276. (https://doi.org/10.1016/j.jad.2003.11.006)

36 Kroenke K, Spitzer RL \& Williams JB. The PHQ-9: validity of a brief depression severity measure. Journal of General Internal Medicine 200116 606-613. (https://doi.org/10.1046/j.15251497.2001.016009606.x)

37 Lowe B, Decker O, Muller S, Brahler E, Schellberg D, Herzog W \& Herzberg PY. Validation and standardization of the generalized anxiety disorder screener (GAD-7) in the general population. Medical Care 200846 266-274. (https://doi.org/10.1097/ MLR.0b013e318160d093)

38 Hamilton M. The assessment of anxiety states by rating. British Journal of Medical Psychology 195932 50-55. (https://doi. org/10.1111/j.2044-8341.1959.tb00467.x)

39 Buysse DJ, Reynolds CF 3rd, Monk TH, Berman SR \& Kupfer DJ. The Pittsburgh sleep quality index: a new instrument for psychiatric practice and research. Psychiatry Research 198928 193-213. (https:// doi.org/10.1016/0165-1781(89)90047-4)

40 Zeitlhofer J, Schmeiser-Rieder A, Tribl G, Rosenberger A, Bolitschek J, Kapfhammer G, Saletu B, Katschnig H, Holzinger B, Popovic R, et al. Sleep and quality of life in the Austrian population. Acta Neurologica Scandinavica 2000102 249-257. (https://doi.org/10.1034/j.16000404.2000.102004249.x)

41 Johns MW. A new method for measuring daytime sleepiness: the Epworth Sleepiness Scale. Sleep 199114 540-545. (https://doi. org/10.1093/sleep/14.6.540)

42 Sauter C, Popp R, Danker-Hopfe H, Büttner A, Wilhelm B, Binder R, Böhning W \& Weeß H-G. Normative values of the German Epworth Sleepiness Scale. Somnologie: Schlafforschung und Schlafmedizin 2007 11 272-278. (https://doi.org/10.1007/s11818-007-0322-8) https://ec.bioscientifica.com https://doi.org/10.1530/EC-19-0043 (c) 2019 The authors Published by Bioscientifica Ltd

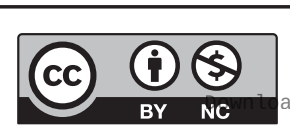

This work is licensed under a Creative Commons Attribution-NonCommercial 4.0 International License. ded from Bioscientifica.com at 04/26/2023 01:14:16PM 
43 Brickenkamp R. Test d2 Aufmerksamkeits-Belastungs-Test (9. Auflage) Göttingen, Germany: Hogrefe, 2002. (available at: https://www. testzentrale.de/shop/test-d2-aufmerksamkeits-belastungs-test.html)

44 Härting C, Markowitsch HJ, Neufeld H, Calabrese P, Deisinger K \& Kessler J. Wechsler Memory Scale - Revised (WMS-R; Wechsler, D., 1987). Bern, Switzerland: Huber, 2000.

45 Aster VM, Neubauer A \& Horn R. Wechsler Intelligenztest für Erwachsene. Deutschsprachige Bearbeitung und Adaptation des WAIS III von David Wechsler. Frankfurt, Germany: Pearson Assessment, 2006.

46 Castaneda AE, Tuulio-Henriksson A, Marttunen M, Suvisaari J \& Lönnqvist J. A review on cognitive impairments in depressive and anxiety disorders with a focus on young adults. Journal of Affective Disorders 2008106 1-27. (https://doi.org/10.1016/j.jad.2007.06.006)

47 Roca M, Vives M, Lopez-Navarro E, Garcia-Campayo J \& Gili M. Cognitive impairments and depression: a critical review. Actas Españolas de Psiquiatría 201543 187-193.

48 Puertas Mdel C, Martinez-Martos JM, Cobo M, Lorite P, Sandalio RM, Palomeque T, Torres MI, Carrera-Gonzalez MP, Mayas MD \& Ramirez-Exposito MJ. Plasma renin-angiotensin system-regulating aminopeptidase activities are modified in early stage Alzheimer's disease and show gender differences but are not related to apolipoprotein E genotype. Experimental Gerontology 201348 557-564. (https://doi.org/10.1016/j.exger.2013.03.002)

49 Kunzel HE. Psychopathological symptoms in patients with primary hyperaldosteronism - possible pathways. Hormone and Metabolic Research 201244 202-207. (https://doi. org/10.1055/s-0032-1301921)

50 Ter Horst JP, Carobrez AP, van der Mark MH, de Kloet ER \& Oitzl MS Sex differences in fear memory and extinction of mice with forebrain-specific disruption of the mineralocorticoid receptor. European Journal of Neuroscience 201236 3096-3102. (https://doi. org/10.1111/j.1460-9568.2012.08237.x

51 Dumeige L, Storey C, Decourtye L, Nehlich M, Lhadj C, Viengchareun S, Kappeler L, Lombes M \& Martinerie L. Sexspecificity of mineralocorticoid target gene expression during renal development, and long-term consequences. International Journal of Molecular Sciences 201718 E457. (https://doi.org/10.3390/ ijms18020457)

52 Kanashiro-Takeuchi RM, Heidecker B, Lamirault G, Dharamsi JW \& Hare JM. Sex-specific impact of aldosterone receptor antagonism on ventricular remodeling and gene expression after myocardial infarction. Clinical and Translational Science 20092 134-142. (https:// doi.org/10.1111/j.1752-8062.2009.00094.x)

Received in final form 6 March 2019

Accepted 13 March 2019

Accepted Preprint published online 13 March 2019 https://ec.bioscientifica.com

https://doi.org/10.1530/EC-19-0043
(C) 2019 The authors Published by Bioscientifica Ltd
This work is licensed under a Creative Commons Attribution-NonCommercial 4.0 International License. ded from Bioscientifica.com at 04/26/2023 01:14:16PM 